\title{
DA CIDADE DO MODO TER DE EXISTÊNCIA À CIDADE DO MODO SER DE EXISTÊNCIA: PREÂMBULO A UM DEBATE GEOGRÁFICO-FILOSÓFICO SOBRE A CIDADE
}

\author{
Samarone Carvalho Marinho*
}

Resumo: Preâmbulo a um debate geográfico-filosófico sobre a cidade. Num primeiro momento tematiza-se a questão da socialidade produzida a partir de uma lógica socioespacial presente nas relações humanas. Em seguida, verifica-se que a expressão socioespacial dessas relações ganha matizes diversos na cidade. Em face disto, e apresentado no terceiro momento, argumenta-se que específicos estágios nas formas das relações humanas acabam por tecer formas específicas de experiência geográfica dos indivíduos na cidade.

Palavras-chave: Cidade. Socioespacialidade. Cidade do modo ter de existência. Cidade do modo ser de existência.

\section{WAYS OF EXISTENCE IN THE CITY: PREAMBLE TO GEOGRAPHICAL AND DEBATE ABOUT THE CITY PHILOSOPHICAL}

Abstract: Preamble to a geographical and philosophical discussion over the city. At first thematizes the question of sociality produced from a sociospatial logic present in human relations. Then there is the expression of these sociospatial win relationships in various shades city. In the face of it, and presented at the third time, it is argued that specific stages in the forms of human relationships ultimately make specific forms of geographical experience of individuals in the city.

Key Words: Daily City. Sociospatiality. City having mode of existence. City mode is in existence.

\section{Introdução}

Decerto, cairemos em filosofismos, se não admitirmos certo valor aporético intrínseco ao esboço de uma análise geográfica aqui proposta. Recordemos que, para os geógrafos, trata-se de um caminho de impasses e incertezas a serem superadas em meio ao valo de décadas que quase impermeabilizou frutíferos e consistentes diálogos entre a Geografia e a Filosofia. Trata-se ainda, e ainda mais, de tentar encontrar, na escaramuça de sentidos, o "real" sentido do fazer geográfico nos dias atuais. Um fazer que se reportar, assim

imagina-se, aos objetos geográficos a serem postos em uso e desuso pelos indivíduos nas suas gamas diversificadas de ações. Encontrar, então, os sentidos à formação do estar-junto, na expressão socioespacial que é a Cidade e no desvendamento de alguns dos seus modos de existir, isto, in media res, é a meta deste artigo. Aos filósofos, o convite em

* Doutor em Geografia Humana pela Universidade de São Paulo. Email: samaronemarinho@hotmail.com 
perscrutar a análise muito além da primeira camada.

\section{O estar-junto e a lógica socioespacial das relações humanas}

As relações existentes entre os indivíduos são partes fundamentais na produção da socialidade. Sejam elas de quais ordens forem (cultural, política, econômica), essas mesmas relações são partes que atuam na produção do estarjunto que inclui o espaço e é incluído pelo espaço $^{1}$. A dialética dessa produção completa-se quando, pela própria vida sendo vivida, o estar-junto é convertido socioespacialmente para fixar dinâmicas de relações que atuam na constituição da individualidade tanto quanto da socialidade em um determinado espaço comum de comunicação. Este espaço revela-se como categoria co-determinante e correlacional para a efetiva realização dos indivíduos no mundo dos homens. O necessitarismo de incluir o espaço para intensificar-complexificar as relações entre os indivíduos demonstra que certa lógica socioespacial é fundante para dirimir a harmonia do conflito relacional na produção dos graus diversos de socialidade. Estes, na fatura, estão diretamente ligados à proximidade e contigüidade socioespaciais entre indivíduos para a produção de formas de desenvolvimento de si e dos grupos nos quais estão inseridos.

Alfred Schutz (1979) mostranos que 0 ambiente comum de comunicação é relativo às pessoas que se encontram nele e o próprio ambiente funciona como a contrapartida (als ihr Gegenüber) da realização individual-social dessas mesmas pessoas. Nas entrelinhas, fica evidente a lógica socioespacial produtora da socialidade que na dependência de menor ou maior aproximação entre os indivíduos ela mesma, a socialidade, se intensifica. O mundo da vida diária, o mundo comum ao gênero humano, se dá como a um apelo de restituição de suas próprias objetivações (trabalho, arte, técnica, etc. $)^{2}$ enquanto reassunção de seus atos comunicativos em prol da facticidade retornada na forma de momentos de consubstanciação entre o ser (sociedade) e o existir (espaço). Essa facticidade retornada como "atos comunicativos em que o Eu se volta para os outros" (Schutz, 1979: 161) na realização de si e do grupo, no contato subordinante-subordinativo com o entorno (espaço geográfico), remete à socialidade, bem como à magnitude das relações socioespaciais, em que tanto indivíduo quanto sociedade formam o mundo (ampliam seu eixo de relações) formando-se, transformando-se através da elevação sensível circunstanciada pelos atos objetivos, pois comunicativos (o trabalho, na acepção marxiana, um deles).

Aquele anúncio feito certa vez por M. Santos (1996) de que o estar-junto dentro de uma área contínua tem reflexos na maneira como a espacialidade se dá na forma como a individualidade evolui e no modo como a corporeidade é sentida -, remete-nos às práticas e percepções socioespaciais adesivas à vida diária dos indivíduos, o seu cotidiano vivido. Essas 
práticas e percepções retornam, à vida diária, enquanto referencial racionalemocional em que, ao mesmo tempo, o pragmatismo das ações e as paixões humanas imersas em gestos biofísicos são responsáveis pelos atos comunicativos na constituição da localização e da situação (pelos dados objetivos da corporeidade), da consciência de si e dos outros (pelos dados subjetivos da individualidade) e dos atos subjetivos-objetivos em si para a realização individual-social e socialespacial nos lugares (pelos aspectos socioespaciais - proximidade e distância produtores da socialidade). De início, vêse que a compleição espacial do cotidiano, em sua forma complexizada (a citadina), é marcada pela contigüidade e/ou afastamento entre os indivíduos para a conformação dos eventos necessários à fatura multiescalar dos espaços de relações, sejam estes de pequeno porte (ruas, vilas, bairros, povoados, cidades pequenas) ou de grande porte (as cidades médias e cidades grandes, em si). Os feixes de realizações objetivadas (trabalho, ciência, arte, comunicação) atuam nesses espaços de maneira mais ou menos universal na significação, organização e sentido socioespacial do cotidiano, bem como, no elã dialético que fortalece o estar-junto, mesmo na diferença de projetos existentes entre os grupos para a edificação da socioespacialidade.

Campo de relações humanas de comunicação, o estar-junto tem sua expressão geográfica assentada naquele lugar social ${ }^{3}$ de dimensões absolutas, relativas e relacionais de que nos fala 0 geógrafo A. C. da Silva (1991). Absolutas, pois se põem como corporeidades únicas; relativas, pois as individualidades são diferenciais umas das outras e remetem a cada corporeidade uma coloração diferenciada; e relacionais porque o modo de vida intersubjetivo entre indivíduosindivíduos, indivíduos-grupos e gruposgrupos, exige uma contrapartida socioespacial para efetivar a mediação do individual-individual com $\mathrm{o}$ individualsocial para a conformação sempre em processo da realidade geográfica. Logo, pode-se dizer que "o homem não existe, isoladamente ou socialmente, sem o espaço que representa e define" (Silva, 1991: 25-26). O homem, dotado de socioespacialidade, tem aí o seu modo de vida esquadrinhado numa compleição sígnica, onde situar-se é considerar o lugar social sempre em formação, que, mediante a dinâmica multiescalar de relações, os eventos produzidos através de atos comunicativos, a todo instante, amplia a socialidade entre os indivíduos, mesmo esta se dando de forma desigual.

A experiência geográfica do "nós", mesmo que diferencial na potência das ações, remete às várias formas de apreensões (imagéticas, sensoperceptivas, processuais etc.) que 0 indivíduo utiliza para realizar a si e o ambiente comum na comunicação com os outros. Essa experiência, motivada pela relação transindividual, eclode na efetiva significação processual de lugares sociais que nos revelam a socialidade como realidade geográfica, devir das ações que reporta à realização de grupos e do mundo dos homens. Espaço da vida sempre em processo, o lugar social é um verdadeiro espaço geográfico através do qual e com o qual o gênero humano se evidencia. Um espaço de relação que, 
tomando de P. George (1969: 42), "associa o vivido ao representado, a realidade ao mito". Um espaço relacional no qual os grupos engajados na produção e reprodução racional-emocional de suas práticas intercambiam pragmatismo e espontaneidade para a confabulação dialético-criativo das significações humanas que penetram cada objeto geográfico.

Uma vez penetrado o objeto geográfico pelas significações humanas, o lugar social transmuda-se em uma esfera plena de significados onde as solicitações (exigências morais, políticas, culturais) se estabelecem para forçar o indivíduo, em sua socioespacialidade, a um envolvimento humano (em todas as esferas) fora de seu espaço íntimoresidencial, fora de sua esfera de significados familiar, para a confabulação de usos variados daquele objeto. É, parece-nos, fora do núcleo socioespacial primevo (o ethos familiar), que o lugar social se forja em um "agrupamento de espaços funcionalmente complementares ou similiares, apresentando uma ou diversas características de unidade" (George, 1969: 45). Tais espaços são das mais diversas montas e estão na dependência do valor que cada grupo imprime à participação da parte (os espaços complementares e similares) ao conjunto das relações socioespaciais como um todo (o lugar social, em si) para a facticidade das objetivações humanas à fatura, ao mesmo tempo diversa e una, do mundo dos homens. O lugar social surge, então, como mediação entre uma realidade geográfica e a sua facticidade demonstrável pelo aspecto socioespacial no qual o estar-junto está mergulhado.

\section{A Cidade: a expressão socioespacial do estar-junto}

Qual lugar social expressa dinamicamente a socioespacialidade do estar-junto? A cidade. O ir e vir aporético em exposição demonstra-nos que a expressão socioespacial do estar-junto, em termos contemporâneos, ganha contornos especiais com a cidade. Pois a partir dela certa relação social manifestase geograficamente como lugar social, onde 0 modo de socialização das objetivações (em muito reveladas nos objetos geográficos) se apresenta num quadro dialético de transformação contínua da realidade geográfica que é. É a ela que nos reportaremos a partir de agora.

Max. Sorre (1967), em seu livro O homem na Terra, certa vez observou que de todas as obras humanas, a cidade é a que mais rigorosamente sofreu dos conflitos, pelo fato de ser a expressão mais completa da vida social. O autor quer, nessa assertiva, nos demonstrar que a cidade é o lugar originário da produção dos mais diversos tipos de socialidades ${ }^{4}$. Como nos disse recentemente M. Santos (2004), a cidade é o lugar que, com sua gama infinita de situações, é a fábrica de relações numerosas, freqüentes e densas. Relações que têm muito a ver com as percepções múltiplas que cada pessoa ou grupo tem do tempo e do espaço na constituição de possibilidades diferentes de utilização de ambos para a produção de relações sociais no lugar social chamado cidade. Com tais 
percepções, a experiência geográfica do "nós" na cidade se complexifica. Essa complexificação remete simultaneamente ao âmbito da materialidade - o campo material das ações pragmáticas e contingenciais que circundam os indivíduos; eis o mundo dos objetos geográficos em si - e da imaterialidade - campo imaterial que diz respeito as ações poíeticas (aquelas ações gestoras da poíēsis que, por aproximação a Lukács em Introdução a uma Estética Marxista, é a manifestação dos atos humano-criativos que elevam a consciência humana) resignificadoras do campo material; eis o mundo das ações em si. Ambos, campo material e campo imaterial, compõem o campo objetivo que é a cidade.

Esse campo objetivo que é a cidade, não é detido como matéria estanque, algo hipostático, mas sim, tomando de J-P. Sartre (1963), compreendido como totalização-em-curso (aqui, para nós, o ininterrupto processo de situar grupos e indivíduos no movimento histórico globalizante na formação socioespacial das cidades que realizam o mundo), pois o estar-junto entre os indivíduos e os grupos tem em si a animer capaz de reconfigurar processualmente a forma-conteúdo da cidade, espaço de existência onde a socioespacialidade do estar-junto se dá enquanto configuração diferencial e conflitiva, aderentes à potência de realização de cada grupo num pedaço do território a cada momento histórico. A cidade, desse ponto de vista, é uma construção humano-social, que se dá como relação entre indivíduos-indivíduos, indivíduos-grupos, grupos-grupos. Cada qual com seus interesses em voga na participação diferenciada à formação social-espacial do ambiente citadino.
Nestes termos, a totalidade que o lugar social (a cidade) pode ser mediante 0 olhar escalar - quando a partir daí identifica-se as partes (bairros, distritos, condomínios etc.) e as relações diferenciadas entre as mesmas para a constituição do Todo heterogêneo, isto é, a cidade, em determinada trama de relações $^{5}$ - é o resultado final-provisório de uma totalização-em-curso, que não é, unicamente, um retorno ao lugar social como materialidade exteriorizada, mas sim o lugar social complexificado pelas relações humanas que enlaçam objetos geográficos já constituídos e herdados de tempos outros (campo material), aos usos diversos que os mesmos podem assumir no tempo hodierno mediante a poíesis que os animam (campo imaterial).

A clarificação dos termos supracitados traz à baila o caráter de premente síntese-provisória da intervenção humana, pela relação, para a realização dos aspectos dialéticos que envolvem objetos geográficos e ações que compõem a cidade. Numa realidade empírica, p. ex., com o vazio de vida humana na cidade (Sewell, no Chile, e Nova Iorque-MA, no Brasil, p. ex.), tem-se - resultado final-provisório de uma totalização. A totalidade realizada aí - o projeto dos moradores de esvaziamento da cidade (seja por questões políticas, Nova Iorque-MA, Brasil; seja por questões econômicas, Sewell, Chile) - tende a ser superada dentro do movimento historicizante da totalização-em-curso: em uma dada realidade, esvaziada a cidade, faz-se necessário realizar outra totalidade (a constituição de novos sítios geográficos 
que demarcam a re-fundação de Sewell, Chile e de Nova Iorque-MA, Brasil) que será um outro estágio do processo interminável e espiráleo que constitui a totalização (reconstituído os novos marcos das cidades - Sewell, Chile e Nova IorqueMA, Brasil - faz-se necessário a habitação e coabitação das mesmas). Assim, a cidade, lugar social de apropriações multiescalares, por si própria se constitui como objeto incompleto se elidida ou enfraquecida a rede de relações (políticas, econômicas, sociais, culturais) existentes entre indivíduos e grupos que lhes dá vida e lhes imprime marcas humanas. Nestes termos, a cidade nunca é reduzida apenas ao campo material de um mundo apenas material. Seria um abandono de sem sentidos. O mundo das totalidades, mediado pela(s) cidade(s), é processo contínuo, um mundo subordinantesubordinativo, apropriado e reapropriado mediante o valor (político, econômico, social, cultural) dado pelos indivíduos e grupos na fatura relacional do mesmo.

Quando A. C. da Silva (1991) nos fala da trama de variações que é o lugar social - este manifestado enquanto multiplicidade de relações sincrônicas e diacrônicas - quer nos mostrar que tais variações se expressam como seres e relações, pois são estes que expressam, outrossim, a diversidade de signos em processos existentes na cidade. $O$ humano-social, em termos de relações objetivadoras (trabalho, arte), anima a cidade remetendo, à mesma, tanto a uma manifestação pragmática quanto a uma manifestação espontânea com que os seres (humanos) dotam 0 ambiente citadino de pulsação humana, criando, a partir daí, as variações que remetem à valorização histórica da cidade. Uma cidade, por outro lado, com ausência de variações de ritmos (sejam eles mais lentos ou mais velozes) tende a cair na mudez da anistória. "O lugar social não existe sem o grupo social que the é próprio, como ter, ser, estar e haver." (Silva, 1991: 32). Sabe-se que, da ausência da dinâmica socioespacial, certo endeusamento do retorno de uma suposta cidade ideal como querem muitos dos urbanistas $^{6}$, por si só não se sustenta, haja vista que um ambiente citadino em existência isolada (como uma cidade ausente de dinamismo humano ou como uma epifania do belo arquitetônico em si) concorre para a hipóstase do processo formativo da cidade.

A cidade é valorizada em função do seu processo de formação socio-espacial quando os indivíduos humanos estão inseridos nesse processo. É quando as contradições saltam aos olhos e atacam o corpo e os sentimentos e a racionalidade, pois, com a vida una e múltipla presente em cada agente da cidade (indivíduos, grupos etc.), os conflitos se interpõem entre os mesmos, os interesses se superpõem uns aos outros, as intencionalidades afloram em processos. Uma cidade enevoada de luta entre os mais diferentes agentes é-nos constantemente apresentada. Uma luta em ebulição, não um campo de guerra como querem nos fazer crer os catastrofistas midiáticos ${ }^{7}$, necessária à conformação de novas demandas à formação social-espacial dos lugares prenhes de apropriação e reapropriação por aqueles indivíduos empobrecidos por uma lógica pragmático-normativa à 
conformação, igualmente, da vida diária a ser vivida e tributária a mesma de novos sentidos. A cidade, entendida assim, deixa de ser encarada como uma ilusão estereoscópica e como sucessão de imagens fílmicas produzindo o efeito de uma "cidade-colagem", de pseudoconvívios seccionados tão desejados pelos urbanistas do dito "desenvolvimento urbano pós-moderno" (Harvey, 2005). O convívio passa a ser, e sempre o foi desde os primórdios da história humana que açambarca a cidade ${ }^{8}$, premente de uma harmonia do conflito não concessionária aos privilégios de uns poucos que utilizam o território, à especulação pura aos seus usos privativos totais. O convívio em meio a essa harmonia conflitiva dar-se-á com a utilização do território pelo e no qual as contradições entre grupos se estabelecem na criação de novas dinâmicas de coexistência, sejam estas indesejáveis para uns ou fundamentais para a sobrevivência de outros.

Em um caso específico analisado pelo geógrafo J. C. Suzuki $(1996)^{9}$ o modo de vida de determinados agentes (moradores de um conjunto habitacional em Rondonópolis-MT, no estudo do geógrafo), na luta para se (re) situarem ao novo modo de vida apresentado na cidade, demonstra-nos que os processos conflitivos nos quais as temporalidades estão envolvidas são prementes de mudanças a cada apropriação do pedaço do território como modo de "realizar-se", mesmo que relativamente, na cidade. Nos termos de análise feita sobre a cidade pela geógrafa A. F. A. Carlos (2004: 20), estaria gestada, aí, "a reafirmação da cidade enquanto espaço social", pois se trataria da realização do ser social [a cidade que se realiza como construção humanosocial] ao longo do processo histórico.

Outrossim, advogar a favor da cidade como o lugar social prenhe do encontro de múltiplas socialidades não pressupõe estabelecer condições peremptórias (sejam elas estimuladoras de planejamentos centralizadores, segmentários etc.) para a afirmação de uma cidade perfeita ao convívio socioespacial. Mesmo Aristóteles (1997), com sua "cidade ideal" ecoada nos Livros VII e VIII de A Política, já trazia a certeza de que uma cidade tinha por base a dialética dos modos de vida constituídos pelas escolhas dos seus habitantes ${ }^{10}$. Escolhas que, para nós, podem determinar tanto a proximidade quanto 0 distanciamento entre os indivíduos numa mesma extensão à conformação da socialidade. Nesse quadro de contigüidade e de distância, a cidade em seu cotidiano vivido é una e múltipla. Una, porque é o espaço da vida de todos, mesmo que o projeto não seja comum; múltipla, porque os pedaços do território (os bairros, as periferias etc.) permitem dizer, em alusão a A. C. da Silva (1995), que viver é continuamente abrir espaço (em relações socioespaciais múltiplas), desde o da habitação até o da vida afetiva. São os indivíduos na investigação da materialidade, imprimindo razão e emoção para a mudança, a cada tempo de nova apropriação, do campo material que compõe a cidade.

São Tomás de Aquino, citado por Rouanet (1993: 420), certa vez disse: 
"ousa servi-te de tua razão". Sentença deveras incompleta nos dias atuais, se não reclamarmos: ousa pôr-te ao lado da razão, com emoção. Parece ser na cidade que esse reclame se faz ouvir com afinco. A razão, só a razão e apenas ela só, põe em risco a socialidade. Não basta um plano de racionalização puro para que o leque de escolhas ao estar-junto fixe o quadro de ações no espaço comum de convívio. Tal plano tornar-se-ia reflexo de um quadro estreito para as ações, empobrecendo a socialidade. É necessária a presença da emoção, gestora da razão emocionante $^{11}$, trazida por aqueles indivíduos empobrecidos à fixação de novas formas de socialidade a fim de assegurar uma comunicação mais densa entre os mesmos ao encontro resignificador do espaço da vida, adensado pelo estar-junto. A cidade precisa desse encontro para permanecer enquanto cidade de intensos dinamismos socioespaciais, lugar social da coexistência dos grupos em seus diversos matizes (econômicos, culturais, políticos). E ter por base a criatividade e a espontaneidade como ações poíēticas que imprimam riqueza à pragmática estabelecida ao mundo, parece ser o princípio norteador do enriquecimento das relações socioespaciais.

Por um lado, temos a espontaneidade, em resposta àqueles que a imaginam como um fazer sem finalidade e caótico, que é uma pugna pela integração dos indivíduos empobrecidos à "realização concreta de sua vida no mundo da matematização" (Santos apud Leite, 2007). Por outro lado temos a criatividade, em resposta àqueles que a vêem como monopólio de intelectuais, que é a expressão da vida humana realizada todos os dias em face do "mundo do cálculo" (Santos apud Leite, 2007). Ambas parecem nos permitir ver a cidade, uma "cidade real" onde os grupos humanos se põem como grupos sociais, expressões do lugar social, que determinam e que o determinam como conjunto de relações socioespaciais (Silva, 1991). Tal conjunto de relações socioespaciais será mais denso à medida que a espontaneidade permita a comunicação entre os indivíduos obrigando-os à intercâmbios criativos na fatura do estar-junto.

\section{As formas de experiência geográfica do "nós" na cidade}

A cidade como local onde as contradições da sociedade se manifestam (Lefebvre, 2008), ajuda-nos a compreendê-la, paradoxalmente, como o lugar do encontro (Santos, 2004). Um encontro que se sustenta na harmonia do conflito e não num aspecto totalmente harmonioso das ações à reorganização e/ou mudança dos objetos. Daí imaginarmos que, na dialética entre ações repetitivas e ações poíēticas, a experiência geográfica do "nós" na cidade pode aparecer, pelo menos, sob duas formas diversas. Duas formas que são reveladas, assim nos parecem, no cotidiano vivido. $\mathrm{Na}$ primeira forma identificamos a princípio, no círculo de relações socioespaciais, um "eu" e um "outro" - na composição do "nós" - atidos apenas às trocas mercadológicas quando há o predomínio da experiência da cidade nos seus aspectos de consumo conspícuo e 
individualismo, se e somente se. A "cidade do modo ter de existência", se sobressai. $\mathrm{Na}$ segunda forma idealiza-se, dentro do círculo de relações socioespaciais, um "nós" enlaçado tanto pelas exigências político-culturais (participação popular, manifestações de rua etc.) quanto pelas exigências metafísicas (a consciência de si, o aumento do vigor do eu) que chamam os indivíduos a experienciar a cidade nos seus aspectos de partilha e solidariedade. A "cidade do modo ser de existência", seria a possibilidade. Enquanto uma é projeto concretizado (a cidade do modo ter de existência) a outra é possibilidade de realização (a cidade do modo ser de existência). Vejamos as mediações para a explicitação das duas formas de experiência geográfica do "nós" na cidade.

Erich Fromm (2008), em Ter ou Ser?, chama-nos a atenção para dois modos fundamentais de existência, que dizem respeito a duas diferentes espécies de orientação para com o "eu" (por aproximação, o indivíduo) e o "mundo" (por coerência interna, a realidade geográfica). Esses modos fundamentais de existência concernem, concomitantemente, às duas formas de orientação cósmico-filosófico ao entendimento da relação estabelecida, durante boa parte da história humana, entre o primeiro termo (o indivíduo) e o segundo termo (a realidade geográfica). 0 autor explica-nos que no "modo ter de existência" o relacionamento do "eu" com o "mundo" é de avidez e posse, cuja relação é obsedante. O "eu", no modo ter de existência, quer tudo e todos, inclusive a si mesmo (Fromm, 2008). Tudo "é" sua propriedade. Isto nos soa como a relação individual-individualista que demonstra o aspecto da construção solitária do indivíduo numa relação funcionalista com - espaço de existência. Na medida contrária, E. Fromm (2008) nos diz que no "modo ser de existência" o "eu" está em contraste tanto com o "ter", na maneira de uma apropriação possessiva do mundo pelo homem, quanto com o "aparecer", derivada dessa apropriação possessiva a favor das aparências ilusórias daí surgidas.

A problemática proposta pelo filósofo atém-se a interrogar a exacerbação do "ter" na construção de elos entre os indivíduos, a interpelar o monopólio do "ter" na condução dos modos de vida e não, necessariamente, questionar a necessidade do "ter" como um dado para a vida. Sobre esta última sentença, o autor nos é claro: "Viver sem ter alguma coisa é virtualmente impossível" (Fromm, 2008: 42). A questão parece-nos, não é o "ter" em si, mas as formas, os tipos de relações que se estabelecem entre os indivíduos (se mais obsedantes ou não) para a concepção de tal "ter", o qual, sob a égide da ética da competição e do consumismo, reduz a experiência da cidade a uma totalidade ilusória da vida humana. Parece-nos ser esse o debate de fundo na obra de Fromm. Assim sendo ele nos permite pensar, mediante o modo ter e o modo ser, em uma experiência da cidade centrada em torno de coisas (a cidade do modo ter), cuja experiência do cotidiano se dá em termos de laceração, e outra centrada em termos de pessoas (a cidade do modo ser), cuja experiência do cotidiano quer ser possibilidade de uma vida mais humana.

O cotidiano vivido, dos que encontram, um dia após outro, a 
expressão da permanência criativa nas ruas e becos da cidade tende a colocar a socialidade entre uma vida baseada no máximo consumo de bens e serviços produzidos, recaindo nos ditames econômico-pragmáticos, e uma vida que vislumbra relações sociopolíticas transformadoras dos indivíduos no ambiente comum de comunicação. Para nós, nessa "encruzilhada", a diferença entre "ter" e "ser" é uma diferença entre uma socioespacialidade centrada no cotidiano enquanto preconceito (em que há uma identificação imediatista "do 'ser' na cidade" com "o 'ter' e o 'consumir' na cidade") e outra centrada no cotidiano enquanto possibilidade (cujas potências humanas podem se revelar num aspecto de co-existência entre as várias formas de "estar" na cidade; ou escaramuçar os limites dessas formas de "estar"). De um lado, uma socialidade com alicerces em um cotidiano esquemático e repetitivo (Lefebvre, 2001); do outro, uma socialidade imaginada a partir do cotidiano como "lugar de descoberta" (Santos, 1993) e "espaço da vida" (Silva, 1995). Ambas implicam formas diferentes de experiência geográfica do "nós" na cidade. Pensemos cada uma delas.

Em aproximação a Agnes Heller (1982), dois elementos constituem a estrutura da vida diária. São eles: o pragmatismo e o economicismo. Eles interagem entre si fomentando formas específicas de experiência geográfica do "nós" na cidade. O desempenho de tarefas que resultem exclusivamente úteis $e$ proveitosas no ambiente comum, incide numa relação utilitarista entre os indivíduos à conformação de específicas formas de socioespacialidades. O primado da imediatez, à busca pela pragmática dos atos humanos, parece direcionar-nos a um cotidiano lacerado, o da ética da competição e o da pressão pelo status. Este cotidiano, por sua vez, está impregnado, como nos deixa entrever $A$. Heller (1991), de um sentido de luta por si mesmo, cada indivíduo na construção isolada da individualidade, impulsionando a uma luta contra os outros. A socioespacialidade do estar-junto está, aí, sob os auspícios do modo ter que conforma em vários níveis a "cidade do modo ter de existência".

$\mathrm{Na}$ cidade do modo ter de existência a rotina mecânica na qual os atos humanos se deixam levar produz, por um lado, o efeito de desinteresse in facto pela cidade, isto na ordem da ação poíētica, e por outro, fixa os indivíduos no apego competitivo pela cidade, isto na ordem da ação repetitiva. A cidade converte-se, assim nos parece, numa teia de relações utilitaristas nas quais os indivíduos elevam seus desejos e ambições econômicas à última potência. Nessa forma de experienciar geograficamente a cidade os indivíduos correm o risco de se inscrevem apenas na dimensão produtiva da vida (no sentido restrito admitido por parte dos economistas), ou seja, do processo de produção de coisas e do seu consumo ad nauseam. Sustentar uma socioespacialidade aderente, se e somente se, no modo ter é depositar neste todas as possibilidades de realização individualsocial na cidade. Na cidade do modo ter de existência, a socioespacialidade do estar-junto não prescinde dos cuidados básicos estruturantes do "ter-mais" e do "aparecer-mais" (alimentação, vestuário, veículo etc.) como princípios norteadores do convívio no ambiente comum de 
comunicação. Na verdade, ajuda-nos ainda E. Fromm (2008), supervaloriza-se a conservação desses cuidados básicos (na forma de consumo conspícuo) em relação à permanência provisória (sobrevivência), em detrimento dos atos humanos (partilha, inter-relação, comunhão etc.) que remetem real valor à sua permanência criativa (liberdade) no mundo humano.

Alguns indivíduos na cidade do modo ter de existência, na constituição de sua socialidade, vivem a cidade como compartimentação do convívio em espaços particularizados (condomínios fechados, enclaves urbanos, "ilhas de opulência"12 etc.). Tal compartimentação soa-nos como "um querer apartar" o conflito das relações socioespaciais empobrecendo a socialidade, o que torna, outrossim, a experiência geográfica do "nós" privilégio de um quadro restrito de indivíduos (as "elites obesas" em seus usos exclusivistas do espaço geográfico; resorts, paraísos fiscais, espaços simulacros etc.). Assim parece-nos, quando, dentro de um ambiente comum de comunicação, indivíduos pecuniosos (empresários, empresas, especuladores, financeiras etc.) acreditam que enriquecem a sua socialidade e a dos outros por "ser-mais" apenas "tendo-mais". Na verdade, essa relação pecuniária levada ao extremo no espaço social da vida apenas fortalece a cidade do modo ter de existência. Em diálogo transversal com A. Heller (1991: 25) o cotidiano, aí, é a expressão dessa vida diária em que o geográfico é revelado como prática cotidiana do preconceito. Assim, os indivíduos pecuniosos, na realização de si mesmos, detentores de uma lógica segregacional como condição de "ter-mais", satisfazem os prazeres materiais e imateriais no júbilo da cupidez, restituindo apenas à experiência geográfica do "nós" um sentido consumista-contemplativo para com a cidade.

A cidade, concebida desta forma traz, também, ferrenhas normas jurídicas (leis, ementas) e não-jurídicas (índices econômicos, índices de desempenho - "ISOS") que atendam à lógica segregacional dos indivíduos pecuniosos. Esse parece ser o caso das normas governamentais-empresariais que atendem as necessidades das transnacionais de alguns setores (o caso do setor aero-espacial, no que diz respeito à compartimentação e fragmentação do território de quilombolas em AlcântaraMA, no Brasil, p. ex. ${ }^{13}$ ). As empresas, nestes termos, sendo um dos agentes pecuniosos, segmenta e (re) ordena o campo material através das suas ações repetitivas a usos exclusivos de pedaços do território. As normas das empresas são, como já nos avisava M. Santos (2004: 230), "uma das locomotivas de seu desempenho e de sua rentabilidade". Essas normas encontram na época atual forte esteio, paradoxalmente, na chamada "desregulação". Sustentadas na desregulação, as elites obesas aliadas às empresas transnacionais reproduzem o ciclo perverso do modo ter na cidade: produção de coisas que, pelo consumo conspícuo, age em prol dos usos exclusivos e pragmáticos de pedaços do território. Nesse ínterim, a desregulação começa a significar multiplicação do 
número de normas e não, ao contrário da imagem que a acompanha, supressão das normas (Santos, 2004). Estamos bem perto, aí, de ver nas normas (do direito positivo), por extensão a G. Lukács (1976), não a expressão da espontaneidade surgida do nada na vida diária, mas a fixação da pragmática normativa de certos indivíduos (os indivíduos pecuniosos) dos usos exclusivos do território.

A autonomia exigida pelos indivíduos pecuniosos em relação às normas, na desregulação-multiplicação da pragmática normativa dos lugares, parece funcionar em causa única e exclusivamente no "interesse mercantil" (Santos, 2004: 276) que, nas relações transindividuais, rege a precedência das atividades econômico-pragmáticas sobre as demais atividades (político-culturais, $p$. ex.). A experiência geográfica do "nós" em determinados "espaços públicos" (estádios, auditórios, cinemas etc.), por vezes, exigem uma contrapartida econômico-financeira altíssima para a partilha do ambiente comum. Uma ideologia da participação e nãoparticipação, pela violência do dinheiro, nesses "espaços públicos" parece guardar certa similitude com a pragmática normativa que alimenta uma "não-relação com a vida" (Agamben, 2007). As normas, muitas vezes, com 0 apelo ao fator intrinsecamente econômico que as incita, direcionam o estar-junto a um estreito quadro de relações socioespaciais que empobrecem a socialidade.

O pragmatismo e o economicismo como "razões de ser" da cidade remetem-na, aproximando-nos de H. Lefebvre (2001: 43), ao papel clássico de cidade como "rede de circulação e consumo, centro de informações e decisões". Parece-nos, ainda com o autor, uma "ideologia absoluta" (Lefebvre, 2001), um pensamento único sobre as cidades, que reduz o "papel" destas na realização do mundo a um papel funcionalista, da realização direta de exigências materiais. Para nós, realização das formas geográficas enquadrada pelos usos normativos impostos por certas leis (planos diretores, p. ex.) e índices (selos de qualidade ambiental, p. ex.). Parece ser óbvio que, no caminho de concepção da cidade propagado pelo pragmatismo normativo, o imaginário ${ }^{14}$ não seja utilizado ou muito subestimado como um momento pertinente da ação. Uma proposta de usos "alternativos" da cidade, em acordo com as escolhas imaginadas por cada "parte do Todo" à conformação da coexistência no ambiente comum de comunicação, soaria como caos às pretensões dos indivíduos pecuniosos em sua conquista por espaços. Esse apelo por coexistência e co-presença escaparia à pragmática normativa produzindo o efeito de sua rejeição imediata.

Ter e consumir são formas básicas da experiência geográfica do "nós" na cidade ${ }^{15}$, entretanto elas não podem, a toque dos desejos totalitários de indivíduos pecuniosos e de suas normas, ser o "Todo" das estruturas vivas norteadoras do estar-junto. As dinâmicas de relações entre os indivíduos não devem converter apenas a socioespacialidade do estar-junto à cupidez imediata da usura do espaço de existência, transformandonos em meros consumidores de espaços e subespaços (culturais, políticos, 
econômicos). A metáfora utilizada por E.

Fromm (2008: 45) do consumidor enquanto "a eterna criança de peito berrando pela mamadeira", concorre, assim nos parece, à transformação do indivíduo em adorador do "ídolo" consumismo. O império do modo ter de existência impõe a ditadura do consumismo que justifica, assim nos parece, a efemeridade com que as relações socioespaciais são tecidas na cidade. Em um instante quer-se engolir o mundo todo, pela prática econômica da avidez consumista, em outro, ainda não abastecidos pelos consumos de subespaços, exige-se mais consumos. Uma espiral perversa que impõe um cotidiano vivido enquanto prática de constrangimentos às corporeidades e individualidades mais sujeitas ao preconceito.

Esse parece ser o círculo vicioso produzido e reproduzido pelos indivíduos na lógica pragmática da cidade do modo ter de existência. Seria então a hora e a vez de pensarmos outro projeto de cidade e, por extensão, outras formas de estar-junto menos utilitaristas e mais humanas? A princípio (e apenas provisoriamente neste nível), se estabelece o convite para pensarmos a cidade não apenas como "forma pura", objeto espacial visível apenas enquanto materialidade cristalizada, mas, sim, pensá-la como lugar social "das ações e relações sociais em processo, como seqüência lógica ou contraditória" (Silva, 1991: 31). Seqüência lógica, pois a forma-conteúdo dinamiza e dá valores outros, pela complexificação das relações socioespaciais, ao devir histórico na realização desse lugar social. Seqüência contraditória, pois está pressuposto uma totalização-em-curso que, com avanços e regressos às ações para a mudança da materialidade, não impede a pugna entre grupos (indivíduos-indivíduos, indivíduosgrupos, grupos-grupos) na realização de cada parte no "Todo" socioespacial. Esses grupos, tomando de $\mathrm{H}$. Lefebvre (2001: 6), "rivalizam no amor pela sua cidade". Um amor visto como uma atividade criadora e não atividade possessiva, processo autorenovador (lógicocontraditório) da cidade e não aprisionador da cidade. Daí, em âmbito de liberdades totais (e não totalitárias), imaginarmos que para a conformação da partilha relacional de espaços pressupõese uma "trégua" no conflito, à resolução momentânea de apenas algumas de suas infinitas demandas, e não à solução definitiva dele (isto, ao menos em termos de tempo curto). A cidade a que nos referimos é a cidade do modo ser de existência.

A cidade do modo ser de existência encontra-se no plano da possibilidade de realização. Ou seja, tomando de R. S. Rudner (1973), tenta-se encontrar os elementos que manifestam potencialmente a contraditoriedade à hegemonia do modo ter presente na cidade. Pensar que numa cidade o imaginário seja um elemento que possa estreitar as distâncias entre os indivíduos no ambiente comum de comunicação é pensar na manifestação de ações poíêticas para sua realização. Ato intencional e estratégia de convívio entre indivíduos, ainda que o projeto de estar-junto não seja comum, o imaginário torna tolerável, em termos relativos, a partilha geográfica do "nós" na cidade. Cada indivíduo, cada grupo, na vida diária percebida de diferentes formas, concorreria para 
revelar o geográfico como prática cotidiana da possibilidade, do enriquecemento da socialidade no lugar social. Quando N. G. Canclini (2007: 80) nos faz o relato das "quatro cidades discerníveis na capital mexicana"16, deixanos claro que para os indivíduos e os grupos de diferentes matizes o imaginário "tem importância à constituição da cidade" (Canclini, 2007: 92). As formas de convívio são múltiplas e conflitualmente compartilhadas à constituição da experiência geográfica do "nós" na cidade do modo ser de existência. Assim, quando assegurada a comunicação mínima entre os indivíduos, o cotidiano vivido se enriquece e abre, ele próprio, um leque multiforme para a declaração dos amores, em atos esperançosamente violentos ou não, à realização do modo ser na cidade.

A cidade no modo ser de existência está prenhe de imaginário para que a dinâmica de suas partes em conexão com o "Todo" societário se faça essencial, pois é a partir desse necessitarismo do imaginário (não apenas ele, claro) que a cidade se "move", e é constituída, pela relação, em socialidades em constantes metamorfoses. Exige-se, então, uma interdependência entre os indivíduos que diariamente labutam espontaneamente para viver na cidade, tornando-a mais suportável e promovendo-Ihe a totalização-em-curso. A tolerância, em termos relativos, se faz pertinente quando esta não pressupõe apenas a aceitação conivente com o que o que "é" (a cidade do modo ter) ou "deve ser" (a cidade do modo ser), mas, como muito bem colocado por Paulo Freire (2009: 39), "uma virtude que consiste na convivência com os diferentes para que se possa melhor lutar contra os antagônicos". A possibilidade de realização da cidade do modo ser de existência de certa forma gesta, esperançosamente, a pugna entre os indivíduos empobrecidos e aqueles que empregam o "discurso da acomodação 'pragmática' ao mundo" (Freire, 2009: 188) no intuito, destes últimos, a afirmarem ad nauseam o primado da hegemonia do modo ter na cidade.

A cidade baseada tanto no máximo consumo de bens quanto na rotina no trabalho repetitivo, ajuda-nos, em termos antagônicos, a vislumbrar, no modo ser, a cidade na qual os anseios dos indivíduos concorreriam para o emprego de formas de objetivações humanas criativas, numa identificação relativa com o mundo humano. Duas formas de objetivações aqui são pensadas para fixarmos um caminho que dirime o modo ser à conformação de outra experiência geográfica do "nós" na cidade. Referimonos ao amor (vivido não como egoísmo a dois, mas vivido enquanto relação humana, caracterizada pela partilha de idéias e objetos e pelo entendimento dos indivíduos que dela participam $)^{17}$ e a esperança (entendida não como mera espera mas enquanto impulso racionalemocional que leva em direção à

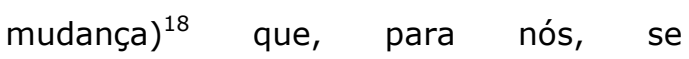
contraporiam à primazia do consumo conspícuo (interesse mercantil em estado puro) e do egoísmo (amor-próprio a caminho da sozinhez), alçando a socialidade à contigüidade onto-física (sustentada por base biológica, mas, também, base cultural e social) 
restauradora do elo entre os indivíduos à uma vivência socioespacial mais dinâmica.

A cidade do modo ser de existência parece pôr-nos diante do amor e da esperança na/pela cidade. Pensar nela com essas formas de objetivação é, dentro dum plano de pertinência da utopia (Santos, 2000), pensar o lugar social como o lugar da partilha dialético-criativa de espaços por parte de todos os indivíduos que, rivalizando no amor à cidade, remetem à constituição da socioespacialidade do estar-junto com todos os objetos: desde os produtos agricultáveis até os cafés, museus e bibliotecas (onde uma específica esfera de significados é cultuada: a esfera letrada). Isto colocado para, em extensão a $\mathrm{H}$. Lefebvre (2001), verificar que os conflitos entre os indivíduos de diferentes visões de mundo não impedem o apego/desapego à cidade e a apreensão intelectualemocional da mesma. Um apego/desapego não-obsedante, mas fulcro à ação poíética. Nestes termos, o conflito é disposto, virtualmente falando, no âmbito das tolerâncias relativizadas. O preconceito que constrange socioespacialmente é o mesmo que traz, in potencia, o germe da reação dos indivíduos empobrecidos em detrimento a uma experiência geográfica do "nós" restrita no pragmatismo.

$\mathrm{Na}$ cidade do modo ser de existência, o amor, não pressupõe o fim do conflito. Não podemos esquecer que ele mesmo, o amor, pode ser tomado por vontades extremadas (seja em prol do narcisismo ególatra ou do hedonismo totalitário) na cidade como um egoísmo a dois, a três, a algumas centenas ou a alguns milhares. $O$ amor pode implicar empatia relativa, com certos graus de afinidades entre os indivíduos na produção de uma socialidade. Entretanto, e aí a relativização da empatia ganha corpo, alguns indivíduos podem estar próximos fisicamente e distantes sócioculturalmente de outros indivíduos, fazendo com que o amor se ponha como o reconhecimento do estar-junto com aqueles que se mostram propícios à construção de projetos densos, para a convivência em determinado ambiente comum. Daí os indivíduos de diferentes matizes rivalizarem entre si no amor ao aprofundamento, seja pelo imaginário ou pela tolerância relativa, da experiência geográfica do "nós" aberta à atividade criadora. Aquela prática da arte de amar analisada por E. Fromm (1973: 166) "como uma atitude amorosa para com todos", pressupõe, para nós, a prática do amor numa complexa dinâmica da socioespacialidade do estar-junto capaz de criar os elos entre os indivíduos mesmo que o projeto seja intermitente. É importante, na esteira da réplica dada por K. Marx e F. Engels à E. Bauer $(2003)^{19}$, não pensar essa prática do amor como um "ídolo" e, por extensão, não pensá-la como prática apenas contemplativa na cidade, mas como a esperança que habita na cidade. Uma esperança que é componente da ação poíética e não uma pura espera. Logo o conflito se faz presente na reordenação do cotidiano vivido enquanto possibilidade que não mais deixa o mundo. E a esperança entendida, não como simples estado veleidoso da alma, mas, como princípio de determinação do homem e da realidade (Bloch, 2006), é a detonadora dos atos dialético-criativos para essa reordenação. 
Em nosso trabalho, interessanos a peculiar esperança geográfica. É uma corruptela que fazemos da noção "esperança geográfica" de E. Bloch (2006: 299-305 $)^{20}$ que serve como detonadora da idéia. Essa esperança geográfica apresentada por Bloch reluzia nas "descobertas", nas ações de descobrir (para ele, "ato pelo qual algo novo é detectado aos olhos de quem chega" América, em suas notas) e inventar (para ele, "ato pelo qual se produz algo novo" pólvora, em uma de suas observações), que nada mais significavam senão a evidência do intervencionismo dândico da cultura européia sobre as demais culturas - qual era pautado na aniquilação laudatória do monismo administrativoreligioso de então (sécs. XVI-XVIII) em face do desconhecido aos seus olhos - a América conquistada. A tal esperança geográfica blochiana tem como seu recinto a capitulação de outros povos ao soerguimento do projeto colonialconquistador europeu. Em termos controversos, apropriamo-nos dessa noção para elevá-la enquanto um dos elementos, junto com o amor, à primazia do modo ser na cidade.

A esperança geográfica que aqui mencionamos, em termos de virtualidade, é a depositária do ressentimento eficaz ${ }^{21}$. Muito mais do que pensar em uma destruição da esperança, vê-mo-la engendrada no ambiente comum de convívio pelos indivíduos que dele tomam partido, para imprimir, pela ação poíētica, o ressentimento eficaz à reconfiguração do modo ter presente no cotidiano em modo ser da vida diária. As geograficidades trazem aquele sentido sartriano de que a esperança existe como parte da ação (Sartre, 1997), isto para efeito de uma mudança significativa ao mundo humano. Daí pensarmos que até mesmo o ressentimento, para que seja eficaz, tem que trabalhar com a esperança dos indivíduos que o propõem. E muitas vezes essa proposição é posta em prática através de atos criativamente violentos, que podem constranger a pragmática normativa imposta por outros indivíduos ao convívio no mesmo ambiente.

Esses atos criativamente violentos, deixa-nos entrever F. Fanon (2005: 81), não são simples atos de vontade, pois exigem, para a sua utilização, condições prévias e muito reais para que eles sejam colocados em prática. Quando M. Santos (2000) remete-nos à apropriação da cultura popular de instrumentos que na origem são próprios da cultura de massas (tvs, rádios, cinemas), dá-nos margem para sustentar que essa apropriação é, em muito, circunstanciada pelo ressentimento eficaz que, numa revanche da cultura popular, produz uma experiência geográfica do "nós" pautada na "experiência da convivência" (Santos, 2000: 144) motivadora dos atos criativos e violentos à apreensão multifacetada do cotidiano. Cabe aos intelectuais e agentes de base popular (movimentos sociais, associação de moradores, conselhos de bairros etc.) primeiro pensar o modo ser de existência como primazia da cidade, e depois identificar no real em movimento as variáveis das quais a razão emocionante possa se valer na ação poíética da vida diária, realizando o primado do modo ser. Em paráfrase a Amílcar Cabral, eis que a teoria, gestada na razão emocionante, 
arma a inteligência dos indivíduos empobrecidos para a conquista de espaços.

A esperança geográfica, interposta a essa conquista, é ato humano que implica um apoio para as ações poíéticas revelarem o necessitarismo da co-existência ao fomento de um estarjunto em que a socioespacialidade se mostra como totalidade heterogênea. A atitude dos indivíduos empobrecidos de persistir criativamente na vida sendo vivida, apropriando-se dos instrumentos da indústria de massa para a consecução de outro fazer artístico e outro fazer político, pressupõe, que, por meio do ressentimento eficaz, a produção de suas próprias formas artísticas e formas de comunicação reagem com força para se opor a tal indústria. A "arte possível" e a "política possível" como "empresas" dos atos humanos esperançosos dos indivíduos empobrecidos, estão circunscritas no terreno da experiência geográfica do "nós". Daí a esperança geográfica que, aproximando-nos da conotação de objetivações duradouras (arte e ciência) de que nos falou certa vez A. Heller (1992), permite a sobrevivência da arte e também da política, enquanto possibilidades realizadas que retornam à vida diária do "eu", bem como aos seus efeitos que sobrevivem na vida diária dos "outros". Isto se dá mediante ação poíética que permite a comunicação da vida do "eu", através da arte ou da política, com a vida do "outro".

Tanto o amor quanto a esperança compõem o quadro utópico para que a cidade do modo ser de existência seja um sintético-provisório de superação constante da cidade do modo ter de existência. A tentativa de se delinear esse porvir passa pela consecução de uma nova visão de mundo (uma nova moral, uma nova política etc.) em que ao mesmo tempo "o homem ponha-se como modo de vida localizado" (Silva, 1991: 41) e faça com que "a centralidade de todas as ações seja localizada no homem" (Santos, 2000: 147). O homem como centro da cidade do modo ser de existência pressupõe que ele "é", quando emprega suas forças essenciais (corpóreas e mentais) numa identificação relativa com o "Todo" societário no movimento de transformarem-se transformando, pela relação, a experiência geográfica do "nós" na cidade. Nestes termos, da retomada do homem como centro das discussões, na cidade do modo ser de existência, a base pragmático-normativa ainda presentes nas ações (com predomínio das ações repetitivas) e nos objetos é incorporada pelos atos poíéticos, circunscrevendo-lhes no âmbito criativo.

Para que o porvir dessas "novas" relações transindividuais na cidade se tornem possibilidade realizada, um programa político que as evidenciem são de suma importância, caso não queiramos que as idéias se esgotem na etapa da retórica. Assim, relativos ao modo ser na cidade, olhar para a esperança geográfica é ver, nela, a crítica desnudar-se na "reorganização" das ações, para um fazer criativo, e na reapropriação dos objetos, no uso criativo. Ambos, ações e objetos, concorreriam para a constituição política da cidade, onde 0 fazer político em sua heterogeneidade torna o evento esperançoso da co-existência possível de ser realizado, e delineia à materialidade graus diversos de usos em acordo com 
essa realização. Uma experiência viva do dia-a-dia, em termos de socioespacilidade do estar-junto, transformaria em momentos mágicos os atos de criar e comunicar, pela arte e pela política, a vida de um ser humano com 0 outro. A esperança geográfica, aí, transmuda-se no "espaço político possível" (Silva, 1986) das ações poíéticas dos indivíduos em produção de outra socialidade no lugar social chamado cidade.

\section{Palavras finais}

Ao fim destas ultimas linhas, admitimos que a falta de uma propedêutica consistente em nosso artigo pareceu soar como a um limite à própria operacionalização de alguns conceitos produzidos. Vide a abertura de algumas noções (esperança geográfica, socioespacilidade, etc) que, até o presente instante, estão no terreno da possibilidade de realização. Basicamente o que se procurou, por meio de aporias ("ser", "ter", "estar", "aparecer"), foi produzir um discurso geográfico aderente e colaborativo ao discurso filosófico no intuito claro de tirar os próprios conceitos e noções do aparente imobilismo e tornálos, sempre por meio da atualização, viáveis à interpretação da realidade geográfica.

Porém, por sabermos do caráter inconcluso deste artigo é que apenas um novo mergulho futuro no real em movimento poderá atenuar tal imobilismo. Sabendo disso, imediatamente, propomos rever os materiais onto-epistêmicos para que o acesso a esse real se torne a epistemologia em estado dinâmico e não em estado inercial. Tal busca implica necessariamente, a disposição em refazer as perguntas à vida sendo vida que poderão redirecionar os conceitos a um posterior estágio de operacionalidade e, por conseqüência, à coerência dos conceitos e das noções. Obviamente, aí, é rever, pari passu, a subordinação dos mesmos às situações do real a serem apreendidos racional-emocionalmente pelos instrumentos de análise. O tempo e - lugar concorrerão para dar maior ou menor consistência às análises, realçando os valores da realidade geográfica com a qual os indivíduos se defrontam.

$$
\text { Por enquanto, dada a }
$$

incompletude da abordagem aqui proposta, parece-nos cedo pensar num final definitivamente conclusivo no tempo e no lugar. Talvez, por isso, e só por isso, os níveis de generalidades sejam esparsos. Eis a consumação circunstancial de nossa perda maior. Assim, a imaginamos. 


\section{NOTAS}

1 "(...) As formas de consciência têm que ver com a individualidade e lhe constituem gamas diferentes, tendo também que ver com a transindividualidade, isto é, com as relações entre indivíduos; relações que são uma parte das condições de produção da socialidade, isto é, do fenômeno de estar junto. Esse fenômeno de estar junto inclui o espaço e é incluído pelo espaço". (Cf. SANTOS, Milton. Por uma geografia cidadã: por uma epistemologia da existência. Boletim Gaúcho, Porto Alegre, RS, n. 21, Ago. 1996, p. 7-14.).

2 Utilizamos o termo objetivação a partir da tradição marxiana (o próprio Marx) e seu alargamento com Lukács. Assim, respectivamente, um e outro: "(...) a objetivação da essência humana [de suas forças essenciais - corpóreas e mentais], tanto do ponto de vista teórico quanto prático, é necessária tanto para fazer humano os sentidos do homem, quanto criar sentido humano correspondente à riqueza inteira do ser humano e natural."(Cf. MARX, Karl. Manuscritos econômico-filosóficos. São Paulo: Boitempo, 2004. p. 110-111.). "A objetividade, portanto, não pode ser separada da subjetividade, nem mesmo na mais intensa abstração da análise estética mais geral.". (Cf. LUKÁCS, Georg. Introdução a uma Estética Marxista: sobre a categoria da particularidade. Rio de Janeiro: Civilização Brasileira, 1978. p. 196.). Assim sendo Georg Lukács (1978) alarga e enriquece a noção de objetivação de K. Marx (2004), quando este encontra no trabalho a primeira e mais evidente forma de objetivação do homem em sua relação com o mundo da vida. Lukács vê na objetivação a possibilidade tanto do estudo do desenvolvimento humano a partir de uma perspectiva ontológica da arte, quanto da luta pela sociabilidade (o termo lukacsiano para relações de objetivação mediadas pela categoria trabalho) promotora do processo de hominização.

3"O lugar social é equilíbrio em equilíbrio, uma relação de causalidade simples ou complexa, como reciprocidade e referência. É também equilíbrio em mudança, ou seja, modificação relativa de um sistema coordenado com referência a um dado campo de forças. Não o pode ser sem pôr-se como o resultado das ações e relações em processo, como seqüência lógica ou contraditória" (p. 31). "O lugar social não existe sem o grupo social que the é próprio, como ter, ser, estar e haver." (p. 32). "O lugar social é uma trama de variações, ou seja, uma complexidade da estrutura do real, manifesta como multiplicidade de relações sincrônicas e diacrônicas existentes num sistema coordenado referido a um campo de forças. Essa trama apresenta variações sociais unitárias (o ser em si como evento singular), de dependência (o ser em relação a outro como evento particular) e equivalentes (o ser em sua manifestação múltipla como evento universal)." (p. 33). (Cf. SILVA, Armando Corrêa da. Geografia e lugar social. São Paulo: Contexto, 1991.).

${ }^{4}$ No capítulo $A$ sociabilidade e o meio geográfico do livro $O$ homem na Terra (1967), Max Sorre demonstra o papel assumido pelos seres humanos no ecúmeno: um poder transformativo de elaboração e reelaboração do espaço habitado pelo homem. A cidade, em seus diversos estilos e formas de organização, surge no ecúmeno como elemento de maior complexificação da vida humana. Nas relações entre seus habitantes estão assentadas ao mesmo tempo a diversidade de ocupações e o alto grau de especialização que marcam a dinâmica socioespacial do lugar.

${ }^{5}$ O geógrafo Élvio Martins (2009) aponta que o importante observar em termos geográficos no que diz respeito à totalidade é que a mesma está encerrada na relação entre o princípio geográfico da escala e o conceito de rede. E é nessa relação que a relação todo/parte em geografia ganha especial sentido. O todo se converte em parte em função da escala a ser considerada, abrindo-se para a rede de relações entre os Lugares. O lugar (a cidade, para nós), nesse ponto de vista, pode tanto ser o todo quanto parte numa trama de relações (rede) maior. Tudo está na dependência da escala de apreensão do real, enlevado por específica epistemologia. (Cf. MARTINS, Élvio. Pensamento geográfico é geografia em pensamento. In: KATUTA, Ângela Massumi (et. al.). Geografia e mídia impressa. Londrina-PR: Moriá, 2009.).

${ }^{6}$ Ao longo do seu livro Condição pós-moderna, David Harvey (2005) analisa as diferentes abordagens ao que se convencionou chamar de planejamento e desenvolvimento urbano. No campo da arquitetura, basicamente, os urbanistas modernos (Ebenezer Howard, Le Corbusier, e discípulos) primaram pela restrição da suburbanização e imediata substituição desta pelo desenvolvimento planejado de novas cidades (Howard) ou pela expansão ou renovação de alta densidade (Corbusier). Ficava em evidência, aí, uma preocupação 
profunda com a racionalização dos padrões espaciais e dos sistemas de circulação para promover uma suposta igualdade, bem-estar e crescimento econômico a todos os que habitavam na cidade. Por outro lado, em seus projetos arquitetônicos, os urbanistas pósmodernos (Leon Krier, Jane Jacobs, dentre outros) teriam como foco principal a visão sobre o espaço como coisa independente e autônoma a ser moldada segundo objetivos e princípios estéticos. Ficaria em evidência o ecletismo do desenvolvimento urbano, permitindo ao urbanista idealizar as "colagens" de espaços necessárias à produção da "cidade-colagem". A "cidade-imagem", sob o império da colagem fragmentária, é um dos preceitos dessa arquitetura. (Cf. HARVEY, David. Condição pós-moderna: uma pesquisa sobre as origens da mudança cultural. 14. ed. São Paulo: Loyola, 2005.).

7 N. G. Canclini (2007) mostra-nos o quanto o poder dos "atores comunicacionais" (televisão, rádio, mídia impressa) ajuda a criar um imaginário da cidade como simulacro. Uma aparência enganosa de uma parte da cidade, pedaços dela (bairros, distritos, vilas etc.), com "os lugares que nunca vamos querer conhecer, porque são emblemas da insegurança, do perigo, algo do qual tem que se escapar." (p. 83). (Cf. CANCLINI, Néstor García. Imaginarios urbanos. 3. ed. 4. reimp. Buenos Aires: Eudeba, 2007.).

8 "A cidade, desde os alvores da era agrária, foi uma criação humana, a obra por excelência; seu papel histórico ainda é mal conhecido". (Cf. LEFEBVRE, Henri. Espaço e política. Belo Horizonte, MG: Editora UFMG, 2008. p. 81.).

9 Fazemos referência ao estudo "Do povoado a cidade: a transição do rural ao urbano em Rondonópolis", no qual o autor indica-nos que o processo de urbanização é marcado por rupturas, heranças do passado e germes do futuro. Dessa forma tal processo, fala-nos o geógrafo, "possui múltiplas temporalidades, tempos históricos que coexistem em um mesmo tempo cronológico" (p. 5). (Cf. SUZUKI, Júlio César. Do povoado a cidade: a transição do rural ao urbano em Rondonópolis. São Paulo: Universidade de São Paulo-USP, 1996. Dissertação de Mestrado.).

10 Fazemos alusão à admissão, por parte de Aristóteles (1997), da escravidão como escolha inelutável. O filósofo estagerita admitia a escravidão na polis e a justificava vendo os escravos como instrumentos de produção ao abastecimento da cidade. (Cf. ARISTÓTELES. Política. 3. ed. Brasília, DF: Editora Universidade de Brasília, 1997.).

11 Essa noção está em diálogo com o que certa vez o geógrafo A. C. R. Moraes (2005) comentou sobre "práxis manipulativa" e "práxis apropriativa". A práxis manipulativa diz respeito a "um saber que propicia o manuseio dos fenômenos, sem captar-Ihes a mecânica" (p. 28). Parecem-nos estar presente, aí, um certo sentido de ver a razão sustentada em um conhecimento advindo da vivência imediata, permitindo reflexões-primeiras sobre o espaço geográfico sem um necessário arcabouço epistemológico para encaminhá-las. Por trás de tal apreensão está aquela geografia primeira vivida pelo indivíduo como uma experiência espacial não nomeada como geográfica (no sentido de um saber científico contemporâneo), mas que tem como base, geograficidades gestadas a partir de relações socioespaciais ainda que não promotoras de significados "científicos". A práxis apropriativa "implica um conhecimento ordenado, sistematizado e padronizado, que visa a apreender a lógica de funcionamento dos fenômenos" (p. 28). A razão, aí, soa como a uma razão racionalizante com instrumentos lógicos encadeados de maneira pragmático-criativo para o alcance de um objetivo científico. Em caso específico, para nós, o objetivo é a produção de um conhecimento geográfico sobre o espaço. Ambas práxis, parecem-nos, se vistas de forma plenamente separadas, concorrerem para realçar apenas o caráter pragmático-normativo de suas apreensões. (Cf. MORAES, Antonio Carlos Robert. Ideologias Geográficas: Espaço, Cultura e Política no Brasil. 5. ed. São Paulo: Annablume, 2005.). A razão emocionante, arvorada num elã emocional-racional, quer ser aquela razão capaz de intercambiar face to face a "práxis manipulativa" com a "práxis apropriativa" para fazer emergir uma práxis formativa que empreenderá uma apreensão emocional-racional do real em movimento. A razão emocionante, sustentada na vida sendo vivida, retorna à mesma na forma de atos de objetivação (trabalho, técnica, arte etc) capazes de imprimir mudanças radicais aos fenômenos.

12 Referimo-nos aos condomínios, enclaves dentro do Todo, que sintetizam materialmente formas específicas de usos individualizados nas cidades. 
${ }^{13}$ A partir de um Plano elaborado pelo Grupo para Implantação do Centro de Lançamento de Alcântara (GICLA) e endossado pelo Decreto $n^{\circ} 7.820$, o Governo do Estado do Maranhão, juntamente com o Ministério da Aeronáutica, no ano de 1980, declarou de utilidade pública para fins de desapropriação uma área de 52 mil hectares, no município de Alcântara-MA, Brasil, para a implantação do CLA (Centro de Lançamento de Alcântara); expropriando cerca de 312 famílias de trabalhadores rurais, deslocando-as compulsoriamente para agrovilas. Estas, de acordo com o Instituto Nacional de Colonização e Reforma Agrária (INCRA), conformavam-se fisicamente num loteamento urbano medindo $25 \mathrm{~m} \times 40 \mathrm{~m}$ e num loteamento rural medindo aproximadamente 14 a 22 hectares. Estes, por sua vez, pelo Estatuto da Terra de 1964, não garantiam o módulo rural básico de 30 hectares para plantio de diversas culturas. As normas estabelecidas pelo plano estatal-empresarial implicam até hoje para os moradores de Alcântara-MA, Brasil, continuadas perdas socioespaciais.

${ }^{14}$ Interpretando de J-P. Sartre (2008), um ato mediado pela imaginação e que é prenhe de intencionalidade em que cada ser consciente elabora, numa relação entre corpo e pensamento, a ação poíētica que principia a sua participação no mundo humano. (Cf. SARTRE, Jean-Paul. A imaginação. Porto Alegre, RS: L\&PM, 2008.). (Cf. SARTRE, JeanPaul. O imaginário: psicologia fenomenológica da imaginação. São Paulo: Ática, 1996.).

15 Em E. Fromm (2008), ainda, a manifestação do ter, ligada ao consumo, diz respeito ao ato de incorporar. (Cf. FROMM, Eric. Ter ou ser?. 4. ed. 1. reimpr. Rio de Janeiro: LTC, 2008.). Ou seja, um nível básico (e originário) para a manutenção da existência esta ligado ao ato de incorporar uma coisa, como por exemplo, comendo-a ou bebendo-a. Toma-se posse do objeto incorporado fisicamente. Isto parece ecoar no sentido de reprodução da vida na cidade, em sua forma básica da reprodutibilidade populacional ao longo do devir histórico. $\mathrm{R}$. Moreira (2007) ajuda-nos a compreender, por uma via aproximativa, o consumo como forma de manutenção da existência ligado ao ato de incorporar, no caso, objetos produzidos. Assim nos diz o autor: "A produção de bens é feita na razão das necessidades de consumo, realizando-se tanto a produção quanto o consumo segundo as leis historicamente determinadas da sociedade próprias à natureza de cada modo de produção. Como o montante dos bens oriundos do processo de produção desaparece sob o ato do consumo, o processo de produção se repete continuamente, isto é, se reproduz sempre." (Cf. MOREIRA, Ruy. Pensar e ser em geografia: ensaios de história, epistemologia e ontologia do espaço geográfico. São Paulo: Contexto, 2007. p. 69.). Produção, reprodução e consumo são formas primevas de manutenção da vida na cidade que garantem relações de base (comer, beber, reproduzir, vestimentas etc.) e expressam o elo desta com o modo ter. Assim, parecem-nos.

16 N. G. Canclini (2007) especificamente no capítulo sobre as cidades multiculturais do livro Imaginarios urbanos, utilizando como exemplo explicativo de cidade multicultural a Cidade do México, relata pelo menos quatro formas de se compreender a complexidade cultural de grandes cidades como a capital mexicana. Segundo o sociólogo as quatro cidades discerníveis na capital mexicana são: 1) "A primeira é a cidade histórico-territorial que açambarcaria os edifícios construídos na época precolombiana e no período colonial e que ainda subsistem"; 2) "A segunda é a cidade industrial que se opõe ao histórico-territorial porque não abarca um espaço delimitado ao modo tradicional, mas sim que se expande com o crescimento industrial, a localização periférica das fábricas e também de bairros operários e de outros tipos de transportes e serviços"; 3) "A terceira é a cidade informacional e comunicacional prevendo que a industrialização já não era o agente econômico mais dinâmico no desenvolvimento das cidades, passou-se a considerar outros impulsos para o desenvolvimento, que são basicamente os informacionais e os financeiros."; 4) "A cidade onde coexistem as três outras cidades e que faz coexistir em ritmo acelerado uma montagem efervescente de culturas de distintas épocas." Entender está última cidade, ainda com o autor, é entender a articulação dos modos diversos de vida e os múltiplos imaginários urbanos que a geram. (Cf. CANCLINI, Néstor García. Imaginarios urbanos. 3. ed. 4. reimp. Buenos Aires: Eudeba, 2007. p. 80-88.).

17 Das múltiplas conotações com o belo (beleza sensível, beleza de sabedoria, belo estético etc) até os significados próprios e irredutíveis da palavra Amor ofertados por diversas visões de mundo (seja pelo platonismo seja pelo cristianismo ou, ainda, panteísmos de todos os matizes), várias são as "teorias do amor". Apenas queremos comentar duas delas: 1) a de G. Simmel (2006), numa transição do Amor do ideal romântico da absoluta unidade para uma concepção formativa do "humano" no homem. "[o amor] pertence a um estágio demasiado elevado da natureza humana para que possamos situá-lo no mesmo plano cronológico e genético da respiração ou da alimentação, ou mesmo do instinto sexual." (Cf. 
SIMMEL, Georg. Filosofia do Amor. 3. ed. São Paulo: Martins Fontes, 2006. p. 123.); 2) e a de E. Fromm (1973), em que o amor é um traço do caráter que deve ser compartilhado entre todos. "(...) o amor deve ele necessariamente existir nas relações que se tenham, não só com a própria família e amigos, mas também com aqueles com os quais se tem contacto, através do trabalho, dos negócios, da profissão." (Cf. FROMM, Erich. A arte de amar. Belo Horizonte, MG: Itatiaia, 1973. p. 166.).

18 A esperança ganha matizes diferentes de acordo com o sistema de idéias no qual fora concebido. Podemos citar alguns exemplos. E. Bloch (2005: 17) a faz categoria básica da filosofia ("A filosofia terá consciência do amanhã, tomará o partido do futuro, terá ciência da esperança. Do contrário, não terá mais saber.") tornando-a o impulso básico da vida que leva o ser humano a transcender o presente e vislumbrar o futuro. (Cf. BLOCH, Ernst. O princípio esperança. v. 1. Rio de Janeiro: EdUERJ: Contraponto, 2005. 3 v.). Em G. Marcel (1959: 33) a esperança é uma correlação de "crédito" entre o sujeito e a realidade, transcendentalmente inseparável do desespero absoluto ao mundo de então. ("Não é menos certo que a correlação da esperança e da desesperança absoluta subsista até o fim. Não me parecem separáveis. Quero dizer que a estrutura do mundo em que vivemos permite, e em certa maneira parece aconselhar, uma desesperança absoluta; mas é só em um mundo deste tipo que pode surgir uma esperança invencível.") (Cf. MARCEL. Gabriel. El mistério ontológico: posicion y aproximaciones concretas. Tucuman: Facultad de Filosofia y Letras/Universidad Nacional de Tucuman, 1959.). E. Fromm (1986: 19-22) ressalta que a esperança não pode ter a conotação de salvação, de uma qualidade de passividade e de "espera", mas, sim, "ter esperança significa estar pronto a todo momento para aquilo que ainda não nasceu e todavia não se desesperar se não ocorrer nascimento algum durante nossa existência." (p. 22). (Cf. FROMM, Erich. A revolução da esperança: por uma tecnologia humanizada. São Paulo: Círculo do Livro, 1986.). É importante observar que parece difícil, para nós, atenuar a "esperança" em uma analítica fromminiana tanto quanto no messianismo que ronda a esperança blochiana, bem como na acepção proto-teológica da esperança de Marcel. Tais concepções de esperança, para nós, trazem à tona o reconhecimento de que a esperança é motivadora da ação poíética. Neste sentido, a esperança, necessariamente, não é uma "ilusão lírica", mas componente da natureza da ação poíética. Tem-se, então, que agir, mesmo em prol de um fim que necessariamente não se torne realizável, é agir esperançosamente "salvando" a ação poíētica do espontaneismo cego e do pessimismo pétreo.

19 A réplica a que nos referimos concerne à resposta dada por K. Marx e F. Engels (2003), n'A sagrada família, a um pequeno ensaio do filósofo alemão Edgar Bauer sobre o amor $(A$ quietude do conhecer). Em síntese Marx e Engels contrapõe-se à Bauer na forma deste querer transformar o amor em um "deus cruel" - "O amor... é um deus cruel que, assim como toda a divindade, quer possuir o homem por inteiro..." (BAUER, 1843 apud MARX; ENGELS, 2003: 31). Ou seja, no ponto de vista crítico marxiano, Bauer ao transformar o amor em "deus cruel" coloca o "amor" à parte do homem como ser, autonomizando-o e lhe remetendo o sentido de objeto, um objeto possessivo e insensato. Contrário à Bauer, Marx e Engels vêem o amor não como abstração, mas como ato humano em "um desenvolvimento real, que ocorre no mundo dos sentidos, entre indivíduos reais". E por fim, reprovam à Bauer, dizendo: "[ele] quer combater com isso não é apenas o amor, mas tudo aquilo que é vivo, tudo que é imediato, toda experiência sensual, toda experiência real..." (Cf. MARX, Karl; ENGELS, Friedrich. A sagrada família: ou A crítica da Crítica crítica contra Bruno Bauer e consortes. São Paulo: Boitempo, 2003. p. 31-34.).

20 Nos termos apresentados por E. Bloch (2006: 303-304) o que caracteriza a "esperança geográfica" são os atos de inventar e descobrir. Na acepção de Bloch, o "inventar" age na alteração dos objetos e intervém neles enquanto o "descobrir" parece se limitar a encontrálos e mostrá-los. Assim: "o descobrir parece não conter mais sonho algum, seria um sonho corrigido de imediato pelos fatos presumidos. O descobridor, no entanto, adota uma atitude meramente observadora (...). O inventor na realidade pressupõe em geral o descobridor, mas não permanece contemplativo como ele, também chamado de explorador. (Cf. BLOCH. Ernst. $O$ princípio esperança. v. 2. Rio de Janeiro: EdUERJ: Contraponto, 2006. 3 v.).

21 Concebemos esse ressentimento não como inteiramente negativo, ou "auto-intoxicação" do ser por uma força nefasta transcendental tanto comentada por M. Sheler (1970) (Cf. SCHELER, Max. L'Homme du ressentiment. Paris: Gallimard, 1970.), mas como um ato de mobilização da ação que traz, dentro da precarização da existência, uma reação ao constrangimento produzido pelos indivíduos pecuniosos (multinacionais, financeiras etc) aos 
indivíduos empobrecidos (movimentos sociais, sindicatos, pobres do dia-dia etc). Ele guarda os germes de ações criativamente violentas por vezes necessárias à reversão, na existência histórico-geográfica, do dano social-espacial produzido pelos agentes hegemônicos. Assim, o aspecto outrora de total negatividade é realçado como ponto relevante à ação poíética e menos moralizante às conseqüências de seus resultados.

\section{REFERÊNCIAS BIBLIOGRÁFICAS}

AGAMBEN, Giorgio. Estado de exceção.

2. ed. São Paulo: Boitempo, 2007.

ARISTÓTELES. Política. 3. ed. Brasília, DF: Editora Universidade de Brasília, 1997.

BLOCH. Ernst. O princípio esperança. v. 2. Rio de Janeiro:EdUERJ: Contraponto, 2006. 3 v.

0 princípio esperança. v. 1. Rio de Janeiro: EdUERJ: Contraponto, 2005. 3 v.

CANCLINI, Néstor García. Imaginarios urbanos. 3. ed. 4. reimp. Buenos Aires: Eudeba, 2007.

CARLOS, Ana Fani Alessandri. O espaço urbano: novos escritos sobre a cidade. São Paulo: Contexto, 2004.

FANON, Frantz. Os condenados da terra. Juiz de Fora, MG: Ed. UFJF, 2005.

FREIRE, Paulo. Pedagogia da esperança: um reencontro com a pedagogia do oprimido. 16. ed. São Paulo: Paz e Terra, 2009.

FROMM, Erich. Ter ou ser?. 4. ed. 1. reimpr. Rio de Janeiro: LTC, 2008.

A revolução da esperança: por uma tecnologia humanizada. São Paulo: Círculo do Livro, 1986.

A arte de amar. Belo Horizonte, MG: Itatiaia, 1973.

GEORGE, Pierre. Sociologia e Geografia. Rio de Janeiro: Forense, 1969.

HARVEY, David. Condição pós-moderna: uma pesquisa sobre as origens da mudança cultural. 14. ed. São Paulo: Loyola, 2005.
HELLER, Ágnes. O Cotidiano e a História. 4. ed. São Paulo: Paz e Terra, 1992.

Sociologia de la vida cotidiana. 3 . ed. Barcelona, Península, 1991.

Para mudar a vida. Felicidade, liberdade e democracia. São Paulo: Brasiliense, 1982.

LEFEBVRE, Henri. Espaço e política. Belo Horizonte, MG: Editora UFMG, 2008.

O direito à cidade. 3. ed. São Paulo: Centauro, 2001.

LEITE, Maria Angela Faggin Pereira (org.). Milton Santos - Encontros. Rio de Janeiro: Beco do Azougue, 2007.

LUKÁCS, Georg. Introdução a uma Estética Marxista: sobre a categoria da particularidade. Rio de Janeiro: Civilização Brasileira, 1978.

Per una Ontologia dell'Essere Sociale. Roma, Riuniti, 1976. v.1.

MARCEL. Gabriel. El mistério ontológico: posicion y aproximaciones concretas. Tucuman: Facultad de Filosofia y Letras/Universidad Nacional de Tucuman, 1959.

MARTINS, Élvio. Pensamento geográfico é geografia em pensamento. In: KATUTA, Ângela Massumi (et. al.). Geografia e mídia impressa. Londrina-PR: Moriá, 2009.

MARX, Karl. Manuscritos econômicofilosóficos. São Paulo: Boitempo, 2004.

MARX, Karl; ENGELS, Friedrich. A sagrada família: ou $A$ crítica da Crítica crítica contra Bruno Bauer e consortes. São Paulo: Boitempo, 2003.

MORAES, Antonio Carlos Robert. Ideologias Geográficas: Espaço, Cultura 
e Política no Brasil. 5. ed. São Paulo: Annablume, 2005.

MOREIRA, Ruy. Pensar e ser em geografia: ensaios de história, epistemologia e ontologia do espaço geográfico. São Paulo: Contexto, 2007.

ROUANET, Sérgio Paulo. Mal-estar na Modernidade. São Paulo: Companhia das Letras, 1993.

RUDNER, Richard. S. Filosofia de la Ciencia Social. Madrid: Alianza Editorial, 1973.

SANTOS, Milton. A Natureza do Espaço: Técnica e Tempo, Razão e Emoção. 4. ed. 1. reimpr. São Paulo: EdUSP, 2004.

Por uma outra globalização: do pensamento único à consciência universal. 3. ed. Rio de Janeiro, Record, 2000.

Por uma geografia cidadã: por uma epistemologia da existência. Boletim Gaúcho, Porto Alegre, RS, n. 21, Ago. 1996.

O espaço do cidadão. 2. ed. São Paulo, Nobel, 1993.

SARTRE, Jean-Paul. A imaginação. Porto Alegre, RS: L\&PM, 2008.

O ser e o nada: ensaio de ontologia fenomenológica. 3. ed. Petrópolis, RJ: Vozes, 1997.

o imaginário: psicologia fenomenológica da imaginação. São Paulo: Ática, 1996.

Crítica de la Razón Dialéctica. Buenos Aires: Losada, 1963. Tomo I. Livro 1.
SCHELER, Max. L'Homme du ressentiment. Paris: Gallimard, 1970.

SCHUTZ, Alfred. Fenomenologia e Relações Sociais. Rio de Janeiro: Zahar Editores, 1979.

SILVA, Armando Corrêa da. Ponto de vista - pós-marxismo e o espaço cotidiano. In: MESQUITA, Zilá; BRANDÃO, Carlos Rodrigues (orgs.). Territórios do cotidiano: uma introdução a novos olhares e experiências. Porto Alegre/Santa Cruz do Sul: Ed. Universidade UFRGS/Ed. Universidade de Santa Cruz do Sul/UNISC, 1995.

Geografia e lugar social. São Paulo: Contexto, 1991.

As categorias como fundamento do conhecimento geográfico. In: SANTOS, Milton; SOUZA, Maria Adélia A. de (coords.). $O$ espaço interdisciplinar. São Paulo: Nobel, 1986.

SIMMEL, Georg. Filosofia do Amor. 3. ed. São Paulo: Martins Fontes, 2006.

SORRE, Max. El hombre en la tierra. Barcelona: Labor, 1967.

SUZUKI, Júlio César. Do povoado a cidade: a transição do rural ao urbano em Rondonópolis. São Paulo: Universidade de São Paulo-USP, 1996. Dissertação de Mestrado. 